\title{
Estrutura e organização de assembleias de Scarabaeinae (Coleoptera, Scarabaeidae) em diferentes fitofisionomias no sul do Brasil
}

\author{
Jonas Darci Noronha de Lima', Vinícius da Costa Silva², Vidica Bianchi', Pedro Giovâni da Silva ${ }^{3}$ \\ \& Rocco Alfredo Di Mare²
}
1. Universidade Regional do Noroeste do Estado do Rio Grande do Sul, Rua do Comércio, 300, Bairro Universitário, 98770-000, ljuí, RS, Brasil. (jonasnoronha@yahoo.com.br)
2. Universidade Federal de Santa Maria, Departamento de Biologia, Laboratório de Biologia Evolutiva, Av. Roraima, 1000, Camobi, 97150-900, Santa Maria, RS, Brasil. (silvavinicius92@gmail.com)
3. Programa de Pós-Graduação em Ecologia, Universidade Federal de Santa Catarina, Rua João Pio Duarte Silva, Córrego Grande, 88040-900, Florianópolis, SC, Brasil. (pedrogiovanidasilva@yahoo.com.br)

\begin{abstract}
Structure and organization of Scarabaeinae assemblages (Coleoptera, Scarabaeidae) in different vegetation types in Southern Brazil. Patterns of species richness, abundance, diversity, equitability and dominance, and the organization in feeding and behavioral guilds of Scarabaeinae fauna were analyzed in three different vegetation types (forest, native field and crop) in northwestern of Rio Grande do Sul, Brazil, among September and November 2012, with the use of pitfall traps baited with different resources (feces, rotting meat and fermented banana). A total of 9,325 specimens were captured, distributed in nine genera and 32 species. The most abundant species were Onthophagus aff. tristis Harold, 1873, Canthidium aff. trinodosum (Boheman, 1858), Canthon aff. fallax Harold, 1868, Canthon lividus Blanchard, 1845 and Deltochilum morbillosum Burmeister, 1848 which represented $65.54 \%$ of the total individuals sampled. The forest showed the highest values of number of individuals and species. The lower richness was observed in the field while the crop showed the lowest abundance of individuals. Scarabaeinae showed qualitative and quantitative differences in their assemblies across vegetation types sampled. The forest showed the highest observed species richness and a fraction of these are unique to this environment, and rarely occurs in other types of ecosystems. In general, the forest has a greater proportion of trophic generalist or copro-necrophagous species in its composition. Another part of this fauna, being largely represented by coprophagous species, is adapted to open environments indicating a change in food guild caused by replacing the forest with pasture. Thus, in a broader context the landscape can play an important role in diversity of dung beetles.
\end{abstract}

KEYWORDS. Dung beetles, forest, native field, crop, attractiveness.

RESUMO. Padrões de riqueza de espécies, abundância, diversidade, equitabilidade e dominância, além da organização em guildas tróficas e comportamentais da fauna de Scarabaeinae foram analisados em três diferentes fitofisionomias (floresta, campo natural e lavoura) na região noroeste do estado do Rio Grande do Sul, Brasil, entre setembro e novembro de 2012, através da utilização de armadilhas de queda iscadas com distintos recursos (fezes, carne em decomposição e banana fermentada). Foram capturados 9.325 espécimes, distribuídos em nove gêneros e 32 espécies. As espécies mais abundantes foram Onthophagus aff. tristis Harold, 1873, Canthidium aff. trinodosum (Boheman, 1858), Canthon aff. fallax Harold, 1868, Canthon lividus Blanchard, 1845 e Deltochilum morbillosum Burmeister, 1848 que representaram 65,54\% do total de indivíduos amostrados. A floresta apresentou os valores mais elevados de número de indivíduos e de espécies. A menor riqueza foi observada no campo, enquanto a lavoura apresentou a menor abundância de indivíduos. Scarabaeinae apresentou diferenças quali- e quantitativas em suas assembleias pelas fitofisionomias amostradas. A floresta abrigou a maior riqueza observada de espécies e uma fração destas é exclusiva deste ambiente, e dificilmente ocorre em outros tipos de ecossistemas. A floresta apresentou uma proporção maior de espécies generalistas ou copro-necrófagas em sua composição. Outra parte desta fauna, representada por espécies coprófagas, está adaptada ao ambiente aberto indicando uma modificação na guilda alimentar causada pela substituição da floresta por pastagem. Dessa forma, em um contexto mais amplo a paisagem pode desempenhar um papel importante na diversidade de Scarabaeinae.

PALAVRAS-CHAVE. Rola-bosta, floresta, campo nativo, lavoura, atratividade.

Os besouros escarabeíneos (Coleoptera, Scarabaeidae, Scarabaeinae) destacam-se pelas suas importantes funções ecológicas realizadas nos ecossistemas terrestres (NichOLS et al., 2008). Eles são considerados como um dos principais promotores do processo de fertilização edáfica, pois atuam na remoção e incorporação de material orgânico em decomposição no solo, tornando os nutrientes novamente disponíveis ao sistema e aumentando a aeração e hidratação edáfica através da escavação de túneis subterrâneos, o que prolonga sua capacidade produtiva (HALFFTER \& MatTHews, 1966; Hofer et al., 2001; Milhomem et al., 2003; Nichols et al., 2008).

Os escarabeíneos são também conhecidos popularmente no Brasil como "rola-bostas" porque muitas espécies se alimentam principalmente de excrementos de animais (coprofagia), processo evolutivo que esteve relacionado à grande diversificação dos mamíferos durante o Cenozoico (HalfFter \& Matthews, 1966; Hanski \& CAMBefort, 1991; Davis et al., 2002; Simmons \& RidSDILLSмITH, 2011). Na região Neotropical, muitas espécies de escarabeíneos consomem também carcaças apodrecidas (necrofagia) e material vegetal em decomposição (saprofagia) (HALFFTER \& MATTHEws, 1966; HALFFTER \& FAVILA, 1993), processos estes que aparentemente teriam derivado originalmente da coprofagia (DAvIS et al., 2002). Por apresentarem a necrofagia como hábito alimentar estes 
besouros estão também relacionados à entomologia forense, sendo considerados como a segunda ordem mais importante na área (HalfFter \& Matthews, 1966; Oliveira-Costa, 2008).

A maioria das espécies de Scarabaeinae pode ser distribuída em três grandes categorias em relação ao modo como utilizam o recurso alimentar na nidificação: escavadoras ou paracoprídeas (espécies que escavam túneis subterrâneos logo abaixo do recurso), roladoras ou telecoprídeas (retiram e rolam uma esfera de alimento até o ninho, onde é enterrada) e residentes ou endocoprídeas (não enterram ou rolam, nidificando no interior do recurso alimentar) (HALFFTER \& MATTHEws, 1966; HALFFTER \& EDMONDS, 1982). Devido ao comportamento de nidificação, muitos escarabeíneos estão envolvidos no controle de alguns endo- e ectoparasitos em agroecossistemas pecuários, pois enterram e consomem massas fecais de grandes mamíferos, eliminando alguns organismos como a moscas-dos-chifres, Haematobia irritans irritans (Linnaeus, 1758), e larvas de nematódeos (Waterhouse, 1974; Flechtmann \& RODRIGUES, 1995; KOLLER et al., 2007). Os escarabeíneos têm sido empregados em estudos de monitoramento de atividades antrópicas, uma vez que apresentam muitas espécies sensíveis às alterações nos ecossistemas naturais (HalfFter \& FaVila, 1993; Favila \& HalfFter, 1997).

Scarabaeinae possui aproximadamente 7.000 espécies descritas em todo o mundo, e continha, até o ano de 2000, 618 espécies registradas no Brasil, das quais 323 foram referidas como endêmicas no país (VAZ-DEMello, 2000). O baixo número de espécies registradas de Scarabaeinae em vários estados brasileiros, incluindo o Rio Grande do Sul (VAZ-DE-Mello, 2000), quando comparado ao total de espécies citadas para o Brasil, mostra a necessidade de serem realizados novos estudos sobre esta importante fauna. Por exemplo, os estados com maior número de espécies registradas foram Minas Gerais (182 espécies e 10 endemismos), Amazonas (177 e 29 endemismos), Rio de Janeiro (137 e 10 endemismos) e Rio Grande do Sul apresentava (79 e 5 endemismos) (VAZDE-Mello, 2000).

O Rio Grande do Sul possui dois diferentes biomas, o Pampa ao sul e a Mata Atlântica na metade norte. Em estudos posteriores desenvolvidos na região sul (DA SILVA et al., 2008, 2009, 2012a, Audino et al., 2011; DA SiLVA, 2011), e na região central (DA SiLVA \& Di MARE 2012, DA Silva et al., 2011, 2012b; Da Silva \& Bogoni, 2014) e nordeste do estado (VIEGAS et al., 2014), mostraram um número significativo de espécies, todavia, incompatível com a lista apresentada por VAZ-DE-MeLLo (2007), uma vez que o autor apresenta um check list das espécies do Brasil e não apenas do Rio Grande do Sul. Para a região noroeste do estado, caracterizada por uma vegetação cuja composição arbórea é do tipo Floresta Estacional intercalada com áreas de vegetação campestre incluindo áreas agrícolas (MARCHIORI, 2002), não consta nenhum trabalho realizado com Scarabaeinae até o momento.

Assim, o objetivo deste estudo foi comparar a riqueza e abundância de espécies de Scarabaeinae em diferentes tipos de habitats no noroeste do Rio Grande do Sul, bem como categorizar o hábito alimentar destas espécies utilizando três tipos de iscas atrativas.

\section{MATERIAL E MÉTODOS}

Caracterização das áreas de estudo. A amostragem foi conduzida em três diferentes componentes de paisagem no campus da Universidade Regional do Noroeste do Estado do Rio Grande do Sul (UNIJUÍ) (28²3'31”S, $53^{\circ} 56^{\prime} 53^{\prime}$ "O), localizado no município de Ijuí, região noroeste do Rio Grande do Sul, Brasil. Conforme os dados obtidos na estação meteorológica do Instituto Regional de Desenvolvimento Rural (IRDER/UNIJUÍ), a temperatura média do mês mais quente é de aproximadamente $22^{\circ} \mathrm{C}$, e a do mês mais frio oscila entre $3^{\circ} \mathrm{C}$ e $18^{\circ} \mathrm{C}$. A precipitação média anual é $1.600 \mathrm{~mm}$ aproximadamente, com pouco mais de $470 \mathrm{~mm}$ somente nos meses de setembro, outubro e novembro, coincidindo os meses mais chuvosos com os meses de coleta.

As amostragens dos escarabeíneos foram realizadas durante a primavera de 2012 (setembro a novembro), uma vez que DA Silva et al. (2012b) registraram maior abundância e diversidade de Scarabaeinae durante esta estação do ano em Santa Maria, região central do Rio Grande do Sul. O estudo foi realizado em três fisionomias onde se realizou o estudo em campo nativo (CA), floresta ciliar (FL) e campo cultivado (LA). O campo nativo totalizava uma área de aproximadamente quatro hectares ( $28^{\circ} 23^{\prime} 34.44^{\prime \prime}$, , $53^{\circ} 56^{\prime} 37.36^{\prime} \mathrm{O}$ ), possuindo vegetação campestre, com predominância de Poaceae e alguns indivíduos de Ateleia glazioviana Baill. (Fabaceae), espécie arbórea pioneira da região sul do Brasil, sugerindo que a área se encontra em um lento processo de sucessão vegetal (EsCAIO et al., 2012). A área também se encontra atualmente abandonada, uma vez que em épocas anteriores ao desenvolvimento do presente trabalho, a área era usada como pastoreio para bovinos. $\mathrm{Na}$

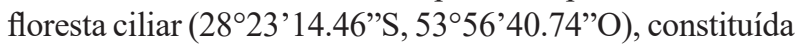
por uma vegetação mais representativa foi composta pelas espécies arbóreas Sebastiania commersoniana Baill. (Myrtaceae) e Matayba elaeagnoides Radlk. (Sapindaceae). $\mathrm{Na}$ fitofisionomia de campo cultivado $\left(28^{\circ} 23^{\prime} 27.86^{\prime}\right.$ 'S, $53^{\circ} 57^{\prime} 7.30^{\prime \prime}$ ), a forrageira Lolium multiflorum L. (Poaceae) foi a planta cultivada durante o período de amostragem.

Coleta dos dados. Em cada fitofisionomia foram instaladas armadilhas de queda (pitfall-trap) iscadas, pois constituem o método mais eficiente para a captura da maior parte das espécies deste grupo (LoBo et al., 1988; HALFFTER \& FaVila, 1993; FaVIla \& HalFFTER, 1997).

As armadilhas foram confeccionadas com recipientes plásticos de $15 \mathrm{~cm}$ de diâmetro e capacidade de $700 \mathrm{ml}$ (enterrados ao nível do solo e com uma cobertura plástica de proteção contra a chuva, amparada por estacas de madeira), que continham solução formalina 
a $2 \%$ com algumas gotas de detergente líquido neutro para a conservação dos espécimes capturados. Sobre as armadilhas foi instalado um recipiente menor, amparado por uma pequena estaca fixada transversalmente em sua parte superior, onde se depositaram as iscas. A atração dos escarabeíneos foi realizada pela utilização de três diferentes iscas (cerca de $25 \mathrm{~g}$ de cada): fezes humanas $(\mathrm{Fe})$, carne bovina apodrecida (Ca) (que permaneceu em potes fechados em temperatura ambiente por no mínimo três dias antes de cada amostragem) e banana fermentada $(\mathrm{Ba})$, as quais compreendem as principais guildas tróficas dos escarabeíneos (HaLfFter \& Matthews, 1966).

Em cada área foram instaladas 30 armadilhas ao longo de um transecto de aproximadamente $200 \mathrm{~m}$, das quais permaneceram ativas por 3 meses, sendo revisadas semanalmente para coleta dos espécimes e reposição das iscas atrativas. A cada $20 \mathrm{~m}$ foram instaladas três armadilhas contendo os três tipos de iscas utilizadas. As três armadilhas de cada conjunto foram instaladas de forma linear, distanciadas em um metro entre si. Ao total foram realizadas 10 amostragens durante o período de coletas. Embora LARSEN \& FORSYTH (2005) sugiram a distância mínima de $50 \mathrm{~m}$ entre armadilhas para uma maior independência, a distância de $20 \mathrm{~m}$ entre conjuntos de armadilhas utilizada neste estudo foi devido à configuração das áreas amostradas, as quais não permitiam uma distância maior entre conjuntos com a mesma quantidade de replicações, situação em que menores distâncias entre as armadilhas podem ser utilizadas na amostragem de Scarabaeinae (DA SILVA \& HERNÁNDEZ, 2015).

Os exemplares coletados foram acondicionados em recipientes com álcool 70\% e levados ao Laboratório de Zoologia/Entomologia da UNIJUI, para triagem, montagem e identificação ao nível de espécie ou morfoespécie. A identificação dos escarabeíneos foi realizada com o auxílio do guia de identificação dos escarabeíneos registrados para Santa Maria, Rio Grande do Sul (DA Silva et al., 2011), bem como por comparação com material depositado na coleção entomológica do Laboratório de Biologia Evolutiva da Universidade Federal de Santa Catarina. Alguns exemplares foram enviados a especialista para identificação (Dr. Fernando Vaz de Mello, Universidade Federal de Mato Grosso - UFMT). O material foi depositado nas coleções entomológicas da UNIJUÍ e UFMT.

Análise dos dados. A proximidade das armadilhas iscadas (um metro entre cada uma) possibilitou a escolha pelos escarabeíneos por um dos três recursos alimentares ofertados (Almeida \& LouZADA, 2009). Desta forma, as espécies foram classificadas como coprófagas (espécies em que no mínimo $80 \%$ do número de indivíduos coletados ocorreram em armadilhas com fezes humanas), necrófagas (espécies em que pelo menos $80 \%$ dos indivíduos foram amostradas em armadilhas com carne bovina apodrecida), saprófagas (quando pelos menos $80 \%$ dos indivíduos da espécie foram capturados nas armadilhas iscadas com banana fermentada) e generalistas (espécies não enquadradas nos grupos anteriores) (AlMEIDA \& LoUZADA, 2009; DA SILVA \&
Di MARE, 2012). Desta análise foram excluídas as espécies singletons (espécies com somente um indivíduo coletado) e doubletons (espécies com dois indivíduos coletados). A guilda comportamental das espécies de Scarabaeinae seguiu a literatura especializada (HALFFTER \& EDMONDS, 1982; Doube, 1991).

O método de rarefação foi conduzido com o objetivo de padronizar o número de indivíduos e comparar a riqueza de espécies (HULBERT, 1971) entre os três tipos de fitofisionomias amostrados, e também em relação aos tipos de iscas utilizados para a captura dos escarabeíneos. Este procedimento foi conduzido no programa R 3.0.0 (R Core TeAm, 2013) e foram calculados os intervalos de confiança a $95 \%$ para cada uma das curvas a fim de comparar estatisticamente os resultados obtidos.

A partir do número de espécies e de indivíduos obtidos em cada coleta, foram feitas curvas suavizadas de suficiência amostral para cada fitofisionomia (função Mao Tau do programa EstimateS [Colwell, 2005]), para verificar a eficiência na amostragem. Nesta análise as amostras foram randomizadas 100 vezes. Para estimar o número de espécies de escarabeíneos de cada fitofisionomia foram calculados os estimadores de riqueza não paramétricos Jackknife 1 e 2 (baseados em dados de abundância, utilizando a relação entre o número de singletons e doubletons para as estimativas de riqueza) e Chao 2 (baseados em incidência, utilizando o número de uniques [espécies encontradas em somente uma amostra] e duplicates [espécies encontradas em somente duas amostras] para as estimativas de riqueza) (COLWELL, 2005). Para verificar a significância dos estimadores foi realizado um teste de Qui-quadrado.

Os índices de diversidade de Shannon-Weaver e Simpson, de equitabilidade de Pielou e de dominância de Simpson e de Berger-Parker foram calculados como medidas ecológicas de diversidade, equitabilidade e dominância para a descrição das assembleias de Scarabaeinae amostradas nas três diferentes fitofisionomias. Estes cálculos foram conduzidos no programa PAST v. 1.37 (HAMMER et al., 2001). A fim de verificar a similaridade entre os tipos de isca utilizados nas diferentes fitofisionomias foi realizada uma análise de agrupamento onde foram empregados os coeficientes de Bray-Curtis, para dados quantitativos, e de Jaccard, para dados qualitativos. O método de agrupamento foi o de médias ponderadas, sendo calculado o coeficiente de correlação cofenética de cada agrupamento. Para verificar a significância na formação de grupos foi conduzida a análise de perfil de similaridade. Estes procedimentos foram realizados no programa R 3.0.0 (R CORE TEAM, 2013).

\section{RESULTADOS}

No total foram capturados 9.325 indivíduos de Scarabaeinae, pertencentes a cinco tribos, distribuídos em dez gêneros e 32 espécies (Tab. I). As espécies mais abundantes foram Onthophagus aff. tristis Harold, 1873 (31,09\%), Canthidium aff. trinodosum (Boheman, 1858) 
Tab. I. Tribos, espécies, guilda funcional (GF), abundância absoluta (N) e relativa (\%) de Scarabaeinae (Coleoptera, Scarabaeinae) coletadas em três diferentes fitofisionomias (FL, floresta; LA, lavoura; CA, campo) no município de Ijuí, Rio Grande do Sul, Brasil, entre setembro e novembro de 2012. T, telecoprídea (roladora); P, paracoprídea (escavadora); E, endocoprídea (residente). * indica ocorrência (N<80\%) da espécie principalmente em determinado tipo de fitofisionomia. São fornecidos os índices de Shannon, Simpson, equitabilidade de Pielou, dominância de Simpson e de Berger-Parker.

\begin{tabular}{|c|c|c|c|c|c|c|c|c|c|}
\hline \multirow{3}{*}{$\begin{array}{l}\text { Tribo/espécie } \\
\text { COPRINI }\end{array}$} & \multirow{3}{*}{ GF } & \multicolumn{6}{|c|}{ Fitofisionomia } & \multirow{2}{*}{\multicolumn{2}{|c|}{ Total }} \\
\hline & & \multicolumn{2}{|c|}{ FL } & \multicolumn{2}{|c|}{ LA } & \multicolumn{2}{|c|}{$\mathrm{CA}$} & & \\
\hline & & $\mathrm{N}$ & $\%$ & $\mathrm{~N}$ & $\%$ & $\mathrm{~N}$ & $\%$ & $\mathrm{~N}$ & $\%$ \\
\hline Canthidium aff. aterrimum Harold, 1867 & $\mathrm{P}$ & 21 & 30,43 & 22 & 31,88 & 26 & 37,68 & 69 & 0,74 \\
\hline Canthidium aff. dispar Harold, 1867 & $\mathrm{P}$ & 7 & 14,29 & 23 & 46,94 & 19 & 38,78 & 49 & 0,53 \\
\hline Canthidium aff. taurinum Harold, 1867 * & $\mathrm{P}$ & 25 & 7,23 & 20 & 5,78 & 301 & 86,99 & 346 & 3,71 \\
\hline Canthidium aff. trinodosum (Boheman, 1858) & $\mathrm{P}$ & 316 & 30,47 & 184 & 17,74 & 537 & 51,78 & 1037 & 11,12 \\
\hline Canthidium moestum Harold, 1867 & $\mathrm{P}$ & 39 & 45,35 & 26 & 30,23 & 21 & 24,42 & 86 & 0,92 \\
\hline Chalcocopris hesperus (Olivier, 1789)* & $\mathrm{P}$ & 1 & 100,0 & 0 & 0,00 & 0 & 0,00 & 1 & 0,01 \\
\hline Dichotomius aff. pygidialis (Luederwaldt, 1922) * & $\mathrm{P}$ & 4 & 3,10 & 109 & 84,50 & 16 & 12,40 & 129 & 1,38 \\
\hline Dichotomius aff. sericeus (Harold, 1867) & $\mathrm{P}$ & 137 & 52,69 & 107 & 41,15 & 16 & 6,15 & 260 & 2,79 \\
\hline Dichotomius mormon (Ljungh, 1799) * & $\mathrm{P}$ & 21 & 100,0 & 0 & 0,00 & 0 & 0,00 & 21 & 0,23 \\
\hline Dichotomius nisus (Olivier, 1789) & $\mathrm{P}$ & 7 & 5,47 & 94 & 73,44 & 27 & 21,09 & 128 & 1,37 \\
\hline Ontherus sulcator (Fabricius, 1775) & $\mathrm{P}$ & 46 & 32,17 & 67 & 46,85 & 30 & 20,98 & 143 & 1,53 \\
\hline \multicolumn{10}{|l|}{ DELTOCHILINI } \\
\hline Canthon aff. fallax Harold, 1868 & $\mathrm{~T}$ & 100 & 10,82 & 159 & 17,21 & 665 & 71,97 & 924 & 9,91 \\
\hline Canthon chalybaeus Blanchard, 1845 & $\mathrm{~T}$ & 184 & 47,55 & 117 & 30,23 & 86 & 22,22 & 387 & 4,15 \\
\hline Canthon lividus Blanchard, $1845 *$ & $\mathrm{~T}$ & 691 & 99,28 & 1 & 0,14 & 4 & 0,57 & 696 & 7,46 \\
\hline Canthon luctuosus Harold, 1868 & $\mathrm{~T}$ & 45 & 52,33 & 2 & 2,33 & 39 & 45,35 & 86 & 0,92 \\
\hline Canthon mutabilis Lucas, 1857 & $\mathrm{~T}$ & 1 & 5,88 & 12 & 70,59 & 4 & 23,53 & 17 & 0,18 \\
\hline Canthon ornatus bipunctatus Burmeister, 1873 & $\mathrm{~T}$ & 2 & 9,09 & 3 & 13,64 & 17 & 77,27 & 22 & 0,24 \\
\hline Canthon quinquemaculatus (Castelnau, 1840) & $\mathrm{T}$ & 20 & 66,67 & 6 & 20,00 & 4 & 13,33 & 30 & 0,32 \\
\hline Canthon rutilans (Castelnau, 1840) * & $\mathrm{T}$ & 98 & 84,48 & 13 & 11,21 & 5 & 4,31 & 116 & 1,24 \\
\hline Canthon sp. * & $\mathrm{T}$ & 3 & 100,0 & 0 & 0,00 & 0 & 0,00 & 3 & 0,03 \\
\hline Deltochilum brasiliense (Castelnau, 1840) * & $\mathrm{T}$ & 209 & 100,0 & 0 & 0,00 & 0 & 0,00 & 209 & 2,24 \\
\hline Deltochilum morbillosum Burmeister, 1848 * & $\mathrm{T}$ & 556 & 100,0 & 0 & 0,00 & 0 & 0,00 & 556 & 5,96 \\
\hline Deltochilum rubripenne (Gory, 1831) * & $\mathrm{T}$ & 99 & 100,0 & 0 & 0,00 & 0 & 0,00 & 99 & 1,06 \\
\hline Deltochilum sculpturatum Felsche, 1907 & $\mathrm{~T}$ & 1 & 50,00 & 1 & 50,00 & 0 & 0,00 & 2 & 0,02 \\
\hline \multicolumn{10}{|l|}{ ONITICELLINI } \\
\hline Eurysternus aeneus Génier, 2009 & $\mathrm{E}$ & 17 & 4,89 & 56 & 16,09 & 275 & 79,02 & 348 & 3,73 \\
\hline Eurysternus caribaeus (Herbst, 1789) * & $\mathrm{E}$ & 367 & 96,83 & 1 & 0,26 & 11 & 2,90 & 379 & 4,06 \\
\hline Eurysternus parallelus Castelnau, 1840 & $\mathrm{E}$ & 46 & 59,74 & 28 & 36,36 & 3 & 3,90 & 77 & 0,83 \\
\hline \multicolumn{10}{|l|}{ ONTHOPHAGINI } \\
\hline Onthophagus aff. tristis Harold, 1873 & $\mathrm{P}$ & 39 & 1,35 & 1749 & 60,33 & 1111 & 38,32 & 2899 & 31,09 \\
\hline \multicolumn{10}{|l|}{ PHANAEINI } \\
\hline Coprophanaeus horus (Waterhouse, 1891) & $\mathrm{P}$ & 0 & 0,00 & 5 & 62,50 & 3 & 37,50 & 8 & 0,09 \\
\hline Coprophanaeus milon (Blanchard, 1843) * & $\mathrm{P}$ & 0 & 0,00 & 6 & 100,0 & 0 & 0,00 & 6 & 0,06 \\
\hline Coprophanaeus saphirinus (Sturm, 1826) * & $\mathrm{P}$ & 176 & 96,17 & 4 & 2,19 & 3 & 1,64 & 183 & 1,96 \\
\hline Sulcophanaeus menelas (Castelnau, 1840) & $\mathrm{P}$ & 0 & 0,00 & 3 & 33,33 & 6 & 66,67 & 9 & 0,10 \\
\hline Número de indivíduos & & 3278 & 35,15 & 2818 & 30,22 & 3229 & 34,63 & 9325 & \\
\hline Número de espécies & & 29 & 90,6 & 26 & 81,3 & 24 & 75,0 & 32 & \\
\hline Shannon-Weaver & & 2.54 & & 1.62 & & 1.9 & & & \\
\hline Simpson & & 0.89 & & 0.60 & & 0.7 & & & \\
\hline Equitabilidade de Pielou & & 0.75 & & 0.50 & & 0.6 & & & \\
\hline Dominância de Simpson & & 0.11 & & 0.40 & & 0.2 & & & \\
\hline Dominância de Berger-Parker & & 0.21 & & 0.62 & & 0.3 & & & \\
\hline
\end{tabular}

(11,12\%), Canthon aff. fallax Harold, $1868(9,91 \%)$, Canthon lividus Blanchard, 1845 (7,46\%) e Deltochilum morbillosum Burmeister, 1848 (5,96\%), que representaram juntas $65,54 \%$ do total de espécimes coletados. A tribo Deltochilini foi a mais representativa, 13 espécies distribuídas em dois gêneros (Canthon Hoffmannsegg, 1817 e Deltochilum Eschscholtz, 1822), o que representou $33,73 \%$ do total de indivíduos coletados.

As curvas de acumulação de espécies, levando-se em conta o número de espécies e de indivíduos em todas as amostragens nas diferentes fisionomias, sugerem que o esforço amostral foi satisfatório para todos os habitats. A partir das curvas de rarefação, observou-se que, quando comparados os números de espécies para a menor abundância entre as fitofisionomias (2.818 indivíduos), a floresta apresentou a maior riqueza, seguida pela lavoura e o campo; estas diferenças foram significativas conforme a configuração dos intervalos de confiança a $95 \%$ de cada curva (Figs 1, 2).

Entre as fitofisionomias estudadas, a floresta ciliar (FL) apresentou o maior número observado de indivíduos (35,15\% do total) (Tab. I), distribuídos em 29 espécies, apresentando C. lividus, D. morbillosum e Eurysternus caribaeus (Herbst, 1789) como espécies mais abundantes. Chalcocopris hesperus (Olivier, 1789), Dichotomius mormon (Ljungh, 1799), Canthon sp., 

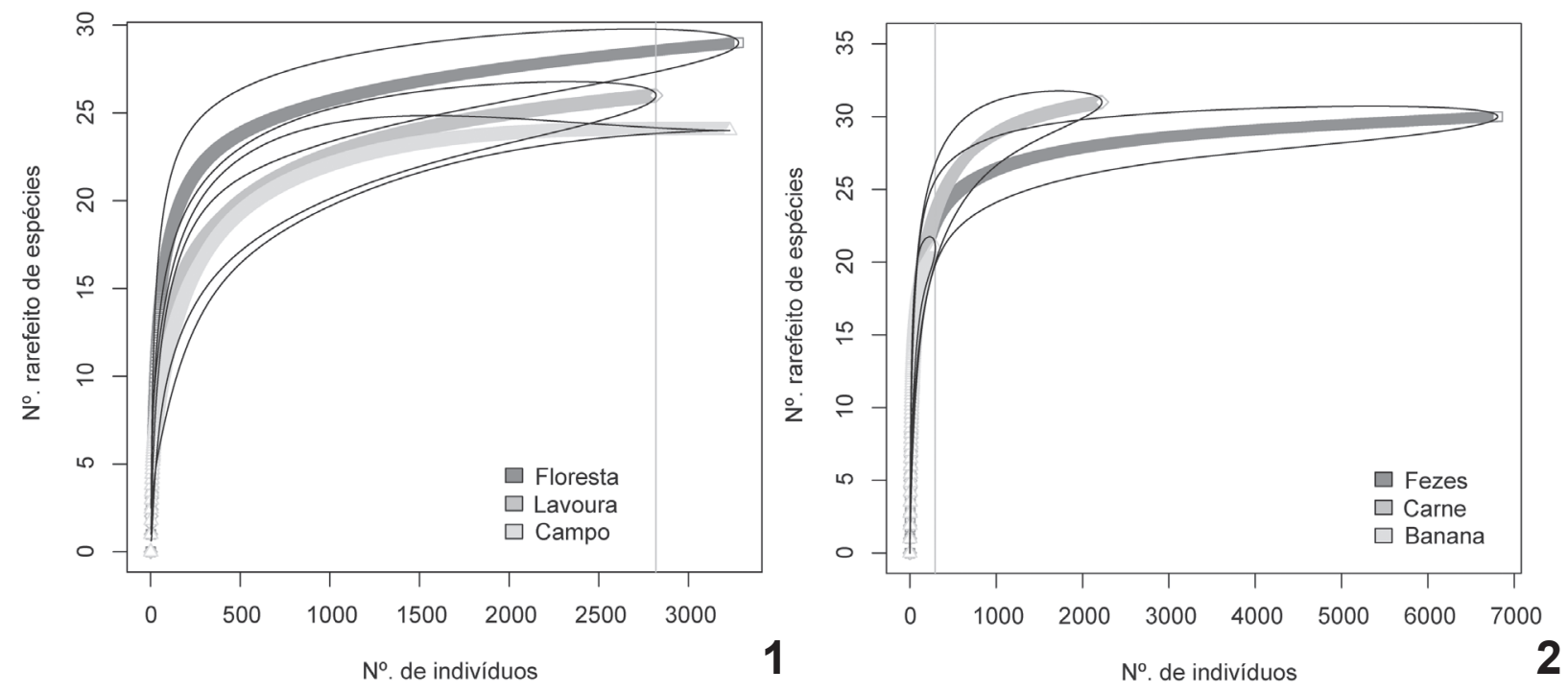

Figs 1, 2. Curvas de rarefação com intervalos de confiança a 95\% para as assembleias de Scarabaeinae amostradas em três fitofisionomias (1) através de armadilhas de solo iscadas com diferentes atrativos (2) no município de Ijuí, Rio Grande do Sul, Brasil, entre setembro e novembro de 2012. A linha vertical indica o ponto de comparação entre as curvas.

Deltochilum brasiliense (Castelnau, 1840), D. morbillosum e D. rubripenne (Gory, 1831) foram exclusivas desta fitofisionomia.

O campo natural (CA) foi responsável por 34,63\% dos indivíduos coletados neste estudo, pertencentes a 24 espécies; $O$. aff. tristis, $C$. aff. fallax e $C$. aff. trinodosum foram as espécies mais abundantes. $\mathrm{Na}$ fitofisionomia caracterizada como lavoura (LA), foram capturadas 26 espécies e $31 \%$ do total de indivíduos amostrados, sendo $O$. aff. tristis, $C$. aff. trinodosum e $C$. aff. fallax as mais abundantes.

Além das espécies acima citadas, que estão restritas à uma determinada fitofisionomia, algumas encontradas nas três áreas amostradas, não exclusivas de um determinado local, apresentaram ocorrência superior a $80 \%$ em uma das fitofisionomias ocupadas, como por exemplo: Canthidium aff. taurinum Harold, 1867 no campo; Dichotomius aff. pygidialis (Luederwaldt, 1922) e Coprophanaeus milon (Blanchard, 1843) na lavoura; C. lividus, Canthon rutilans (Castelnau, 1840), E. caribaeus e Coprophanaeus saphirinus (Sturm, 1826) na floresta.

Entre as iscas utilizadas para a atração dos escarabeíneos, as fezes humanas foram as mais atrativas, incluindo 73,0\% do total de indivíduos capturados (Tab. II), seguida da carne bovina apodrecida $(23,84 \%)$ e da banana fermentada (3,16\%). Em relação ao número de espécies capturadas, a carne apodrecida apresentou o maior número observado (31 espécies), seguida de fezes humanas (30 espécies) e da banana fermentada (21 espécies) (Tab. II). As curvas de rarefação para as iscas utilizadas demonstraram que, no menor número de indivíduos entre as iscas (295), não houve diferença significativa na comparação da riqueza de espécies conforme a configuração das curvas e seus intervalos de confiança a 95\% (Fig. 3).

$\mathrm{Na}$ floresta, as armadilhas iscadas com carne foram as que capturaram o maior número de indivíduos (50,3\%) e C. lividus, D. morbillosum e C. saphirinus foram as espécies mais abundantes. As armadilhas iscadas com excremento humano capturaram $45,3 \%$ dos indivíduos nessa fitofisionomia, cujas espécies mais abundantes foram C. aff. trinodosum, E. caribaeus e Dichotomius aff. sericeus (Harold, 1867). As armadilhas com banana fermentada tiveram o menor poder de atração na floresta, atraindo apenas 4,4\% do total dos indivíduos capturados nesta fitofisionomia. Neste tipo de isca, as espécies mais abundantes foram D. morbillosum, C. lividus e $C$. aff. trinodosum.

No campo, as armadilhas iscadas com fezes humanas mostraram-se mais atrativas nas capturas dos escarabeíneos, representando $87,5 \%$ do total de indivíduos coletados nesta fitofisionomia; $O$. aff. tristis, $C$. aff. fallax e $C$. aff. trinodosum foram as mais abundantes. Nas armadilhas iscadas com carne, $C$. aff. fallax, $C$ aff. taurinum e $C$. aff. trinodosum foram as mais abundantes. Nas armadilhas em que foi oferecida banana fermentada, como atrativo, a maior abundância foi de Canthon chalybaeus Blanchard, 1845, C. aff. fallax e D. aff. pygidialis.

$\mathrm{Na}$ lavoura, as iscas com fezes humanas atraíram mais indivíduos do que as demais, totalizando $88,5 \%$ dos espécimes coletados. As espécies mais abundantes atraídas por este recurso foram $O$. aff. tristis, $C$. aff. trinodosum e $C$. aff. fallax. A isca de carne foi a segunda mais atrativa, totalizando $8,4 \%$ dos indivíduos, atraindo em maiores números $C$. chalybaeus, $D$. aff. pygidialis e $O$. aff. tristis. As iscas com banana fermentada foram responsáveis por $3,1 \%$ dos indivíduos coletados nesta fitofisionomia, sendo $D$. aff. pygidialis, D. aff. sericeus e D. nisus as espécies mais abundantes atraídas a este recurso.

Conforme a classificação das guildas comportamentais para os escarabeíneos (Tab. I), 
Tab. II. Lista de espécies, número de indivíduos e proporção por tipo de armadilhas iscada (banana fermentada [Ba], fezes humanas [Fe] e carne bovina apodrecida [Ca]) e guilda trófica (GT) de Scarabaeinae coletadas em três diferentes fitofisionomias (FL, floresta; LA, lavoura; CA, campo) no município de Ijuí, Rio Grande do Sul, Brasil, entre setembro e novembro de 2012 (T, total; C, coprófaga; N, necrófaga; G, generalista; S, singleton; D, doubleton).

\begin{tabular}{|c|c|c|c|c|c|c|c|c|c|c|c|c|c|c|c|c|}
\hline \multirow{2}{*}{ Espécies } & \multicolumn{3}{|c|}{ FL } & \multicolumn{3}{|c|}{ LA } & \multicolumn{3}{|c|}{$\mathrm{CA}$} & \multicolumn{6}{|c|}{$\mathrm{T}(\%)$} & \multirow{2}{*}{ GT } \\
\hline & $\mathrm{Ba}$ & $\mathrm{Fe}$ & $\mathrm{Ca}$ & $\mathrm{Ba}$ & $\mathrm{Fe}$ & $\mathrm{Ca}$ & $\mathrm{Ba}$ & $\mathrm{Fe}$ & $\mathrm{Ca}$ & $\mathrm{Ba}$ & $\%$ & $\mathrm{Fe}$ & $\%$ & $\mathrm{Ca}$ & $\%$ & \\
\hline Canthidium aff. aterrimum & 1 & 18 & 2 & 0 & 21 & 1 & 0 & 24 & 2 & 1 & 1,45 & 63 & 91,30 & 5 & 7,25 & $\mathrm{C}$ \\
\hline Canthidium aff. dispar & 5 & 2 & 0 & 0 & 22 & 1 & 1 & 15 & 3 & 6 & 12,24 & 39 & 79,59 & 4 & 8,16 & G \\
\hline Canthidium aff. taurinum & 1 & 22 & 2 & 0 & 17 & 3 & 3 & 232 & 66 & 4 & 1,16 & 271 & 78,32 & 71 & 20,52 & G \\
\hline Canthidium aff. trinodosum & 13 & 278 & 25 & 5 & 167 & 12 & 9 & 466 & 62 & 27 & 2,60 & 911 & 87,85 & 99 & 9,55 & $\mathrm{C}$ \\
\hline Canthidium moestum & 8 & 19 & 12 & 3 & 17 & 6 & 0 & 16 & 5 & 11 & 12,79 & 52 & 60,47 & 23 & 26,74 & G \\
\hline Canthon aff. fallax & 8 & 57 & 35 & 0 & 147 & 12 & 10 & 583 & 72 & 18 & 1,95 & 787 & 85,17 & 119 & 12,88 & $\mathrm{C}$ \\
\hline Canthon chalybaeus & 10 & 39 & 135 & 8 & 13 & 96 & 16 & 14 & 56 & 34 & 8,79 & 66 & 17,05 & 287 & 74,16 & $\mathrm{G}$ \\
\hline Canthon lividus & 50 & 102 & 539 & 1 & 0 & 0 & 0 & 4 & 0 & 51 & 7,33 & 106 & 15,23 & 539 & 77,44 & G \\
\hline Canthon luctuosus & 2 & 13 & 30 & 0 & 1 & 1 & 1 & 34 & 4 & 3 & 3,49 & 48 & 55,81 & 35 & 40,70 & G \\
\hline Canthon mutabilis & 0 & 0 & 1 & 3 & 3 & 6 & 1 & 2 & 1 & 4 & 23,53 & 5 & 29,41 & 8 & 47,06 & G \\
\hline Canthon ornatus bipunctatus & 0 & 1 & 1 & 0 & 3 & 0 & 0 & 11 & 6 & 0 & 0,00 & 15 & 68,18 & 7 & 31,82 & G \\
\hline Canthon quinquemaculatus & 0 & 0 & 20 & 0 & 2 & 4 & 0 & 1 & 3 & 0 & 0,00 & 3 & 10,00 & 27 & 90,00 & $\mathrm{~N}$ \\
\hline Canthon rutilans & 2 & 81 & 15 & 0 & 13 & 0 & 0 & 5 & 0 & 2 & 1,72 & 99 & 85,34 & 15 & 12,93 & $\mathrm{C}$ \\
\hline Canthon sp. & 0 & 0 & 3 & 0 & 0 & 0 & 0 & 0 & 0 & 0 & 0,00 & 0 & 0,00 & 3 & 100,00 & $\mathrm{~N}$ \\
\hline Chalcocopris hesperus & 0 & 1 & 0 & 0 & 0 & 0 & 0 & 0 & 0 & 0 & & 1 & & 0 & & $\mathrm{~S}$ \\
\hline Coprophanaeus horus & 0 & 0 & 0 & 0 & 4 & 1 & 0 & 3 & 0 & 0 & 0,00 & 7 & 87,50 & 1 & 12,50 & $\mathrm{C}$ \\
\hline Coprophanaeus milon & 0 & 0 & 0 & 0 & 1 & 5 & 0 & 0 & 0 & 0 & 0,00 & 1 & 16,67 & 5 & 83,33 & $\mathrm{~N}$ \\
\hline Coprophanaeus saphirinus & 6 & 18 & 152 & 0 & 1 & 3 & 0 & 0 & 3 & 6 & 3,28 & 19 & 10,38 & 158 & 86,34 & $\mathrm{~N}$ \\
\hline Deltochilum brasiliense & 8 & 76 & 125 & 0 & 0 & 0 & 0 & 0 & 0 & 8 & 3,83 & 76 & 36,36 & 125 & 59,81 & G \\
\hline Deltochilum morbillosum & 23 & 105 & 428 & 0 & 0 & 0 & 0 & 0 & 0 & 23 & 4,14 & 105 & 18,88 & 428 & 76,98 & G \\
\hline Deltochilum rubripenne & 1 & 37 & 61 & 0 & 0 & 0 & 0 & 0 & 0 & 1 & 1,01 & 37 & 37,37 & 61 & 61,62 & G \\
\hline Deltochilum sculpturatum & 0 & 0 & 1 & 0 & 0 & 1 & 0 & 0 & 0 & 0 & & 0 & & 2 & & $\mathrm{D}$ \\
\hline Dichotomius aff. pygidialis & 0 & 4 & 0 & 24 & 60 & 25 & 7 & 8 & 1 & 31 & 24,03 & 72 & 55,81 & 26 & 20,16 & G \\
\hline Dichotomius aff. sericeus & 3 & 106 & 28 & 23 & 69 & 15 & 5 & 10 & 1 & 31 & 11,92 & 185 & 71,15 & 44 & 16,92 & G \\
\hline Dichotomius mormon & 0 & 20 & 1 & 0 & 0 & 0 & 0 & 0 & 0 & 0 & 0,00 & 20 & 95,24 & 1 & 4,76 & $\mathrm{C}$ \\
\hline Dichotomius nisus & 0 & 5 & 2 & 18 & 60 & 16 & 0 & 27 & 0 & 18 & 14,06 & 92 & 71,88 & 18 & 14,06 & G \\
\hline Eurysternus aeneus & 0 & 16 & 1 & 0 & 56 & 0 & 4 & 265 & 6 & 4 & 1,15 & 337 & 96,84 & 7 & 2,01 & $\mathrm{C}$ \\
\hline Eurysternus caribaeus & 1 & 350 & 16 & 0 & 1 & 0 & 4 & 7 & 0 & 5 & 1,32 & 358 & 94,46 & 16 & 4,22 & $\mathrm{C}$ \\
\hline Eurysternus parallelus & 0 & 40 & 6 & 0 & 27 & 1 & 0 & 3 & 0 & 0 & 0,00 & 70 & 90,91 & 7 & 9,09 & $\mathrm{C}$ \\
\hline Ontherus sulcator & 0 & 44 & 2 & 0 & 66 & 1 & 0 & 26 & 4 & 0 & 0,00 & 136 & 95,10 & 7 & 4,90 & $\mathrm{C}$ \\
\hline Onthophagus aff. tristis & 2 & 32 & 5 & 2 & 1722 & 25 & 3 & 1065 & 43 & 7 & 0,24 & 2819 & 97,24 & 73 & 2,52 & $\mathrm{C}$ \\
\hline Sulcophanaeus menelas & 0 & 0 & 0 & 0 & 2 & 1 & 0 & 5 & 1 & 0 & 0,00 & 7 & 77,78 & 2 & 22,22 & G \\
\hline Número de indivíduos & 144 & 1486 & 1648 & 87 & 2495 & 236 & 64 & 2826 & 339 & 295 & 3,16 & 6807 & 73,00 & 2223 & 23,84 & \\
\hline Número de espécies & 17 & 25 & 26 & 9 & 24 & 21 & 12 & 23 & 18 & 21 & 65,63 & 30 & 93,75 & 31 & 96,88 & \\
\hline
\end{tabular}

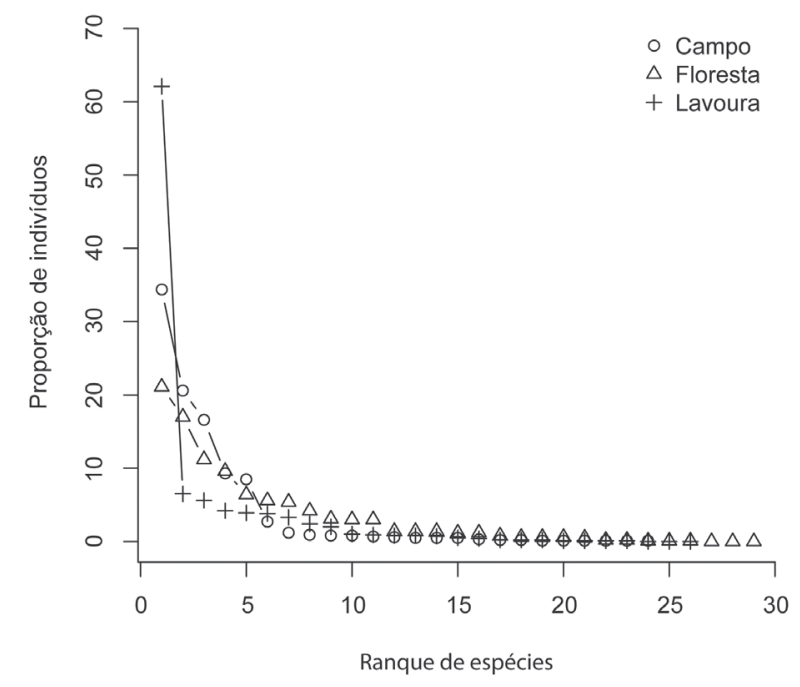

Fig. 3. Distribuição em ranques da abundância proporcional das assembleias de Scarabaeinae amostradas em três fitofisionomias através de armadilhas de solo iscadas no município de Ijuí, Rio Grande do Sul, Brasil, entre setembro e novembro de 2012. A distribuição segue a ordem decrescente de abundância relativa das espécies em cada fitofisionomia. foram capturadas 16 espécies (50,0\%) escavadoras, 13 $(40,3 \%)$ roladoras e três $(9,4 \%)$ residentes. Porém, para as fitofisionomias de lavoura e campo a proporção de escavadoras foi sempre superior às demais guildas $(53,85 \%$ e $54,17 \%$, respectivamente). Na floresta, a proporção de escavadoras e roladoras foi a mesma $(44,83 \%)$. Em todas as fitofisionomias a guilda das espécies residentes foi sempre menor $(10,3 \%, 11,5 \%$ e $12,5 \%$ para floresta, lavoura e campo, respectivamente).

Em relação às guildas tróficas, 15 espécies $(46,88 \%)$ foram classificadas como generalistas, 11 (34,38\%) como coprófagas e quatro como necrófagas $(12,50 \%)$. Nenhuma espécie teve a saprofagia como hábito alimentar principal. Duas espécies não puderam ser enquadradas em nenhuma das categorias tróficas, pois apresentaram número insuficiente de indivíduos, sendo uma doubleton (Deltochilum sculpturatum Felsche, 1907) e outra singleton (C. hesperus).

A análise da diversidade realizada através do índice de Shannon-Weaver (Tab. I) mostrou que os maiores valores foram verificados na fisionomia de floresta, seguida por campo e lavoura. A equitabilidade apresentou o mesmo 
padrão, indicando que e lavoura possui uma baixa uniformidade na distribuição de abundância das espécies pela ocorrência de espécies dominantes como $O$. aff. tristis, por exemplo. Consequentemente, os maiores índices de dominância de Simpson e de Berger-Parker foram observados também na lavoura, corroborando a menor diversidade e equitabilidade nesta fitofisionomia. A floresta apresentou os menores valores de dominância para ambos os índices. Tais resultados podem ser visualizados pela configuração da distribuição de abundância das espécies de Scarabaeinae pelas diferentes fitofisionomias (Fig. 3).

Conforme os valores obtidos pelos estimadores de riqueza (Tab. III), na floresta houve uma captura mínima de $85,72 \% \%$ e máxima de $97,38 \%$, enquanto a lavoura apresentou estimativas entre $82,83 \%$ e $95,76 \%$ e o campo entre $83,25 \%$ e $96,25 \%$. Dessa forma, a estimativa máxima de riqueza de espécies na floresta foi de $\sim 34$ espécies, na lavoura de $\sim 31$ espécies e no campo de $\sim 29$ espécies. As diferenças analisadas através de um teste de Qui-quadrado mostram que os valores estimados para a floresta não foram significativos com nenhum dos três estimadores utilizados.
Nas outras duas fitofisionomias algumas diferenças foram estatisticamente significativas.

A análise de similaridade entre os tipos de iscas utilizando dados de abundância das espécies de Scarabaeinae mostra a formação de três grupos (Figs 4, 5). O grupo de maior similaridade foi entre as armadilhas de fezes na lavoura e no campo, seguido das armadilhas de queda iscadas com fezes e carne na floresta. Os demais tipos de armadilhas formaram um terceiro grupo. Quando foram utilizados dados sobre a composição de espécies, houve a separação em quatro grupos distintos (Figs 4, 5). O grupo de maior similaridade foi representado pelas armadilhas iscadas com carne e fezes humanas na lavoura e no campo. O segundo grupo foi formado por todas as armadilhas da floresta. As armadilhas iscadas com banana fermentada no campo e na lavoura formaram cada uma um grupo distinto. O coeficiente de correlação cofenética foi de 0.88 e 0.85 para o agrupamento qualitativo e quantitativo, respectivamente, o que demonstra a alta representatividade dos dendrogramas formados.

Tab. III. Estimativa da riqueza de espécies ( \pm desvio padrão) de Scarabaeinae para as três fitofisionomias amostradas no município de Ijuí, Rio Grande do Sul, Brasil, entre setembro e novembro de 2012. * indicam resultados significativos ( $\mathrm{p}<0,05)$; ns, não significativo.

\begin{tabular}{lccc}
\hline & Floresta & Lavoura & Campo \\
\hline Total observado & 29 & 26 & 24 \\
Observado médio & $22.67 \pm 2.85$ & $18.00 \pm 4.58$ & $17.67 \pm 3.18$ \\
Chao 2 & $31.14 \pm 6.87 \mathrm{~ns}$ & $31.39 \pm 14.47 *$ & $27.68 \pm 11.51 \mathrm{~ns}$ \\
Jackknife 1 & $29.78 \pm 3.90 \mathrm{~ns}$ & $27.15 \pm 5.48 \mathrm{~ns}$ & $24.94 \pm 4.12 \mathrm{~ns}$ \\
Jackknife 2 & $33.83 \pm 4.88 \mathrm{~ns}$ & $30,00 \pm 7.19 *$ & $28.83 \pm 5.22 *$ \\
\hline
\end{tabular}

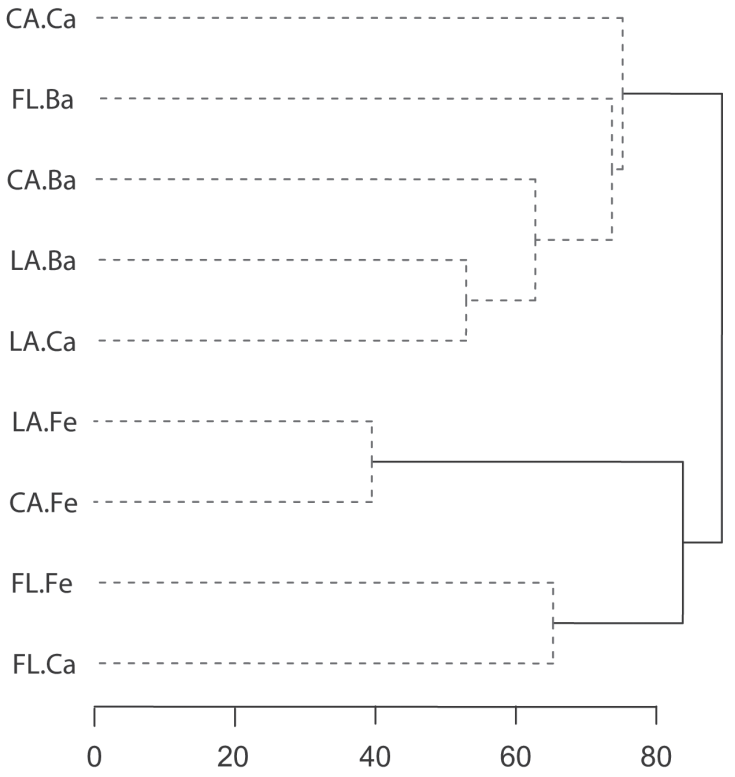

Dissimilaridade de Bray-Curtis

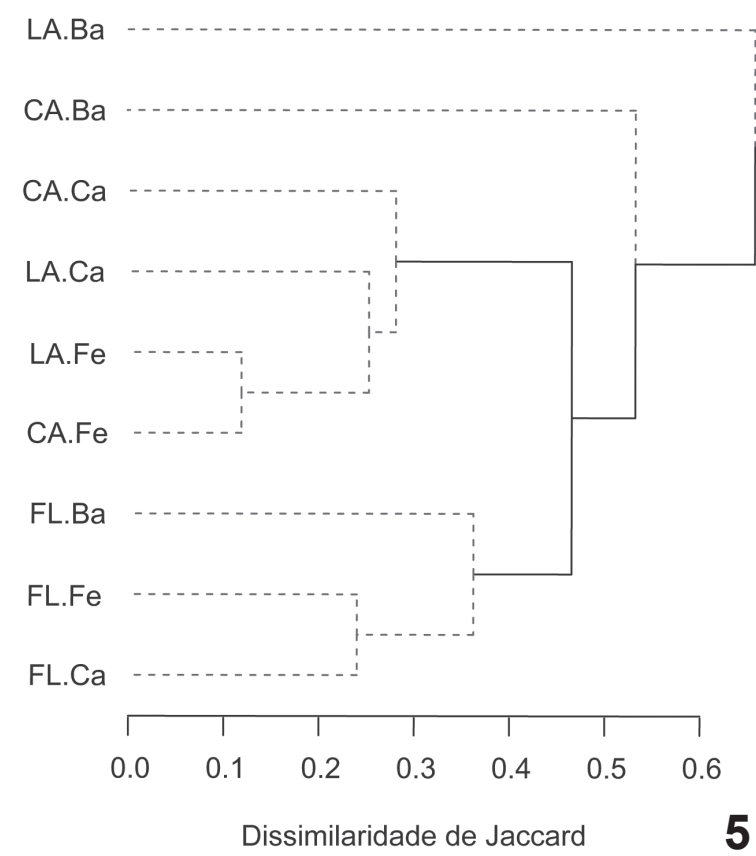

Figs 4, 5. Dendrogramas de dissimilaridade de Bray-Curtis (4) e de Jaccard (5) das assembleias de Scarabaeinae capturadas com armadilhas iscadas com banana fermentada (Ba), fezes humanas (Fe) e carne bovina apodrecida (Ca) nas fitofisionomias de floresta (FL), lavoura (LA) e campo (CA) no município de Ijuí, Rio Grande do Sul, Brasil, entre setembro e novembro de 2012. As linhas pontilhadas evidenciam a formação de grupos estatisticamente diferentes conforme a análise de perfil de similaridade. 


\section{DISCUSSÃO}

A maioria das espécies registradas já foi citada por outros autores para o Rio Grande do Sul. Pesquisas realizadas na região da Campanha, em diferentes ecossistemas como campo nativo, áreas florestadas e áreas de ecótono de campo e floresta (DA SILVA et al., 2008, 2009, 2012a; Audino et al., 2011), apresentaram Onthophagus aff. hirculus Mannerheim, 1829, C. rutilans, Ontherus sulcator (Fabricius, 1775) e C. ornatus bipunctatus como as mais abundantes. Em estudos conduzidos em áreas de campo em Bagé, Rio Grande do Sul, Da Silva et al. (2009, 2012a) registraram 17 e 30 espécies, respectivamente: $O$. aff. hirculus, $C$. ornatus bipunctatus e Canthidium moestum Harold, 1867 foram as espécies mais abundantes. Diferentemente, no presente estudo, a fitofisionomia caracterizada como campo apresentou maior abundância de $O$. aff. tristis, C. aff. fallax e C. aff. trinodosum. Entretanto, tanto neste como nos trabalhos supracitados, destaca-se a maior abundância de espécies coprófagas neste tipo de ecossistema. HALFFTER \& MATHEWs (1966) sugeriram que nestes ambientes há um maior número de escarabeíneos coprófagos devido à presença de grandes mamíferos herbívoros, que ofertariam grande quantidade de excremento.

Da mesma forma, estudos realizados na região central do estado em fragmentos de floresta (DA SiLva \& Di MARe, 2012; DA Silva et al., 2012a) apontaram Canthon latipes Blanchard, 1845, C. aff. trinodosum, Dichotomius assifer Eschschholtz, 1822 e C. chalybaeus como as mais abundantes. $\mathrm{O}$ número de espécies registradas na floresta neste trabalho (29) se assemelha ao verificado por Da Silva \& Di Mare (2012) em fragmentos da Mata Atlântica, em Silveira Martins, região central do estado do Rio Grande do Sul. Estes autores registraram 28 espécies, cujas mais representativas foram $C$. latipes, $C$. chalybaeus e $D$. sculpturatum. A diferença entre este estudo e os demais trabalhos realizados no Rio Grande do Sul, é aproximadamente de $30 \%$, ressaltando provavelmente as diferenças de distribuição geográfica das espécies de Scarabaeinae pelo estado.

A elevada riqueza registrada no ecossistema de floresta pode estar relacionada à presença e/ou maior abundância de diferentes recursos alimentares, como carcaças, frutos em decomposição e excrementos. Dessa forma, a proporção menos desigual do número de indivíduos entre os tipos de iscas na fitofisionomia de floresta sugere que neste tipo de ecossistema a fauna de Scarabaeinae parece apresentar uma composição de espécies onde há um maior número de generalistas em relação ao hábito alimentar (HALFFTER \& MATHEWS, 1966). O grande número de generalistas, necrófagos e saprófagos encontrados em ambientes florestais permite uma maior diversidade de espécies nestes ecossistemas. Outro importante fator é a característica estrutural da floresta quando comparada com ambientes abertos. A presença de árvores pode influenciar o microclima do interior da floresta pela retenção dos raios solares no dossel. Tais aspectos podem ser fundamentais para algumas espécies de Scarabaeinae, as quais são muito sensíveis às mudanças ambientais (HALFFTER \& FaVILA, 1993). A presença, neste estudo, de seis espécies de escarabeíneos restritas à fitofisionomia de floresta corrobora a especificidade de habitat de uma parcela das espécies de Scarabaeinae (HALFFTER, 1991).

As coletas de lavoura apresentaram um maior número observado de espécies em relação ao campo nativo. Tais resultados são contraditórios com os de Lopes et al. (2011), que encontraram elevada abundância e menor riqueza de espécies de Scarabaeinae em área de pastagem abandonada quando comparada com áreas florestais, e os de ALMEIDA et al. (2012), que também observaram uma riqueza de espécies menor em áreas de pastagens exóticas quando comparadas às nativas. A composição de espécies entre lavoura e campo diferiu pela presença de D. sculpturatum e C. milon somente na primeira fitofisionomia. Deltochilum sculpturatum ocorreu também na floresta, sendo singleton como na lavoura e $C$. milon foi registrado somente na lavoura. DA SiLVA et al. (2011) relataram que estas espécies são necrófagas, preferencialmente de áreas campestres; ambas ocorrem com frequência em áreas alteradas no sul do Brasil (DA Silva et al., 2013). A diferença entre as assembleias da lavoura e do campo pode ter ocorrido devido à variação na distribuição espacial destas espécies ou do recurso alimentar preferencial. Porém, a similaridade na composição de espécies destas duas fitofisionomias foi muito alta $\mathrm{e}$ as pequenas diferenças encontradas podem ter acontecido por eventos estocásticos.

Entre as iscas utilizadas para a atração dos escarabeíneos as fezes humanas apresentaram o maior sucesso em relação ao número de indivíduos e a carne apodrecida em relação ao número de espécies. Excrementos de grandes mamíferos são o principal recurso alimentar utilizado pela maioria das espécies de Scarabaeinae (HalfFter \& MatThews, 1966; Hanski \& CAMbefort, 1991; Simmons \& Ridsdill-Smith, 2011). Contudo, a necrofagia em Scarabaeinae é considerada importante em florestas neotropicais, onde a presença de grandes mamíferos é menor se comparada com áreas abertas (Halffter \& Matthews, 1966). Neste estudo, foram encontradas 16 espécies especialistas (11 coprófagas e quatro necrófagas) e 15 generalistas quanto à alimentação. Dessa forma, assim como verificado neste estudo e em Almeida \& Louzada (2009) e Da Silva et al. (2012b), parece haver um número maior (ou similar) de espécies de Scarabaeinae especialistas em relação às generalistas. Este padrão vai de encontro à hipótese de que as assembleias neotropicais de Scarabaeinae possuem maior proporção de espécies generalistas (HALFFTer \& MatTHEws, 1966; HALFFTER, 1991). De uma forma geral, algumas espécies de Scarabaeinae embora sejam generalistas podem apresentar uma preferência alimentar por determinado tipo de recurso (DA SiLVA et al., 2012b). Tanto em relação ao total de indivíduos como em cada fisionomia, observouse um maior número de espécies escavadoras em relação 
às demais guildas. Salienta-se que este padrão, onde há maior número de espécies escavadoras, é comum na região Neotropical (HALFFTER et al., 1992; LouZADA \& LOPES, 1997). A distribuição proporcional das guildas comportamentais parece ser fruto da diversidade local das tribos de Scarabaeinae ocorrentes na Região Neotropical (LouZADA \& Lopes, 1997). Apenas a fitofisionomia de floresta apresentou proporções iguais de escarabeíneos escavadores e roladores, devido à ocorrência restrita de espécies de Deltochilum neste tipo de ecossistema. Tal ocorrência possivelmente causou esta diferença, em relação ao recorrente padrão encontrado para a distribuição das guildas comportamentais de Scarabaeinae, que contém espécies que são amostradas com a utilização de armadilhas de queda iscadas. HALFFTER \& MATHEws (1966) salientam que Deltochilum é um gênero fundamentalmente necrófago, embora existam algumas espécies copro-necrófagas, e suas espécies habitam preferencialmente o interior de florestas.

Entre as espécies coletadas neste estudo e que apresentaram elevada preferência pelo habitat florestal, destacam-se Dichotomius mormon (Ljungh, 1799) que é registrada pela primeira vez para o estado do Rio Grande do Sul (P.G. da Silva, observ. pess.), obtida exclusivamente na floresta, principalmente em armadilhas iscadas com excremento humano. Canthon lividus ocorreu no ambiente florestal, sendo capturada principalmente em armadilhas iscadas com carne apodrecida, seguida de fezes humanas, diferentemente dos resultados encontrados por AUDINO et al. (2011). O hábito copro-necrófago dessa espécie foi também observado em áreas florestadas por DA SiLVA et al. $(2008,2009)$ e AUdino et al. (2011). Canthon rutilans também apresentou maior abundância em área de floresta $(84,48 \%)$ e em armadilhas de fezes humanas, corroborando os dados de Da Silva et al. (2008) e Audino et al. (2011). Canthon ornatus bipunctatus foi capturada principalmente nos ecossistemas campestres, onde apresentou preferência pela isca de fezes humanas, sendo uma espécie comum em áreas com vegetação campestre (DA SiLVA et al., 2009).

A análise de dissimilaridade revelou que existe uma diferenciação qualitativa e quantitativa nas assembleias de Scarabaeinae pelas diferentes fitofisionomias amostradas neste estudo. De uma forma geral, a floresta apresentou composição e abundância diferenciadas das demais áreas nos diferentes tipos de iscas utilizados. As armadilhas de carne e fezes na lavoura e no campo revelaram uma composição muito semelhante, embora não tenha se refletido completamente na abundância dos escarabeíneos atraídos a estas iscas nestas fitofisionomias. Nestas áreas, somente as armadilhas iscadas com fezes humanas apresentaram uma alta similaridade em relação ao número de indivíduos. Dessa forma, os ecossistemas florestais possuem uma distribuição mais semelhante quanto à riqueza e abundância de escarabeíneos, diferindo das áreas campestres, naturais ou cultivadas. Nas áreas abertas, porém, há uma composição de espécies copro-necrófagas ou generalistas associadas às iscas de excremento. Estes resultados também mostram a influência do tipo de habitat e da disponibilidade do recurso alimentar nos diferentes ecossistemas, assim como sugerem HalfFter \& Matthews (1966) e HalfFter \& Arellano (2002).

Com base nos dados observados, a fauna de Scarabaeinae amostrada na região noroeste do Rio Grande do Sul revelou diferenças qualitativas e quantitativas em suas assembleias pelas fitofisionomias amostradas. $\mathrm{O}$ ambiente florestal abrigou a maior riqueza observada de espécies e uma fração destas é exclusiva deste ambiente e dificilmente ocorre em outros tipos de ecossistemas. Em sua maioria, possui proporção maior de espécies generalistas ou copro-necrófagas em sua composição. Contudo, outra parte desta fauna está adaptada ao ambiente aberto, estando, em grande parte, representada por espécies coprófagas. Dessa forma, o contexto da paisagem é muito importante para a fauna de Scarabaeinae, pois a complementariedade de hábitats pode apresentar uma diversidade particular que aumenta a diversidade da paisagem (ALMEIDA \& LouZADA, 2009). Estudos como este, direcionados ao conhecimento da biologia e distribuição de escarabeíneos, são fundamentais para embasar qualquer iniciativa futura de conservação da biodiversidade e de ecossistemas (DA SILVA et al., 2012a) no sul do Brasil.

Agradecimentos. A Dra. Francesca W. Ferreira, Caroline Hartmann, Valdenar Gonçalves, Ronaldo Nunes, Ana Claudia Escaio e Geodeli Corrêa pelo apoio e auxílio (intelectual e logístico) durante o desenvolvimento deste estudo. Ao Dr. Fernando Vaz de Mello, Universidade Federal de Mato Grosso - UFMT, pela ajuda na identificação de alguns exemplares.

\section{REFERÊNCIAS BIBLIOGRÁFICAS}

Almeida, S. S. P. \& LouZADA. J. N. C. 2009. Estrutura da comunidade de Scarabaeinae (Scarabaeidae: Coleoptera) em fitofisionomias do Cerrado e sua importância para a conservação. Neotropical Entomology 38:32-43.

Almeida, S.; LouZada. J.; Sperber, C. \& Barlow, J. 2012. Subtle landuse change and tropical biodiversity: dung beetle communities in Cerrado grasslands and exotic pastures. Biotropica 43(6):704-710.

Audino, L. D.;Da Silva, P. G.; Nogueira, J. M.; Moraes, L. P. \& VaZDe-Mello, F. Z. 2011. Scarabaeinae (Coleoptera, Scarabaeidae) de um bosque de eucalipto introduzido em uma região originalmente campestre. Iheringia, Série Zoologia 101(1-2):121-126.

Borror, D. J. \& Delong, D. M. 1988. Introdução ao Estudo dos Insetos. 1ed. São Paulo, Edgard Blücher. 653p.

Bouchard, P.; Bousquet, Y.; Davies, A. E.; Alonso-ZaraZaga, M. A.; Lawrence, J. F.; Lyal, C. H. C.; Newton, A. F.; Reid, C. A. M.; SChMitT, M.; ŚLIPIŃski, S. A. \& SMITH, A. B. T. 2011. Family-group names in Coleoptera (Insecta). ZooKeys 88:1-972.

Colwell, R. K. 2005. EstimateS: Statistic estimation of species richness and shared species from samples. Version 7.0. Disponível em $<\mathrm{http}$ ://viceroy.eeb.uconn.edu/EstimateS $>$. Acesso em 15.11.2005.

Costa Lima, A. 1952. Insetos do Brasil. Tomo 7. Coleópteros. Rio de Janeiro, Escola Nacional de Agricultura, Série didática. 362p.

DA Silva, P. G. 2011. Dung beetles (Coleoptera: Scarabaeidae: Scarabaeinae) of two non-native habitats in Bagé, Rio Grande do Sul, Brazil. Zoological Studies 50(5):546-559.

Da Silva, P. G. \& Bogoni, J. A. 2014. Dung beetles (Coleoptera: Scarabaeidae: Scarabaeinae) attracted to rotten eggs in the Atlantic forest in subtropical southern Brazil. The Coleopterists Bulletin 68(2):339-342.

Da Silva, P. G. \& Di Mare, R. A. 2012. Escarabeíneos copro-necrófagos (Coleoptera, Scarabaeidae, Scarabaeinae) de fragmentos de Mata Atlântica em Silveira Martins, Rio Grande do Sul, Brasil. Iheringia, Série Zoologia 102(2):197-205. 
DA Silva, P. G. \& HeRnÁNDEZ, M. I. M. 2015. Spatial patterns of movement of dung beetle species in a tropical forest suggest a new trap spacing for dung beetle biodiversity studies. PLoS ONE 10(5):e0126112.

Da Silva, P. G.; Audino, L. D.; Nogueira, J. M.; Moraes, L. P. \& VaZDE-Mello, F. Z. 2012a. Escarabeíneos (Coleoptera: Scarabaeidae: Scarabaeinae) de uma área de campo nativo no bioma Pampa, Rio Grande do Sul, Brasil. Biota Neotropica 12(3):246-253.

Da Silva, P. G.; Garcia, M. A. R. \& Vidal, M. B. 2008. Besouros copronecrófagos (Coleoptera: Scarabaeidae stricto sensu) coletados em ecótono natural de campo e mata em Bagé, RS. Ciência e Natura 30(2):71-91.

2009. Besouros copro-necrófagos (Coleoptera: Scarabaeidae sensu stricto) do município de Bagé, RS (bioma Campos Sulinos). Biociências 17(1):33-43.

Da Silva, P. G.; VaZ-De-Mello, F. Z. \& Di Mare, R. A. 2011. Guia de identificação das espécies de Scarabaeinae (Coleoptera: Scarabaeidae) do município de Santa Maria, Rio Grande do Sul, Brasil. Biota Neotropica 11(4):329-345.

2012b. Attractiveness of different bait to the Scarabaeinae (Coleoptera: Scarabaeidae) in forest fragments in extreme southern Brazil. Zoological Studies 51(4):429-441.

2013. Diversity and seasonality of Scarabaeinae (Coleoptera: Scarabaeidae) in forest fragments in Santa Maria, Rio Grande do Sul, Brazil. Anais da Academia Brasileira de Ciências 85(2):679-697.

Davis, A. L. V.; Scholtz, C. H. \& Philips, T. K. 2002. Historical biogeography of scarabaeine dung beetles. Journal of Biogeography 29:1217-1256.

Doube, B. M. 1991. Dung beetle of Southern Africa. In: Hanski, I. \& Cambefort, Y. eds. Dung beetle ecology. Princeton, Princeton University Press, p.133-155.

Escaio, A. C.; Corrêa, G.; Lima, J. D. N. \& Coelho, G. C. 2012. Emergency and growth of Ateleia glazioveana Baill. Seedlings in direct sowing in an early secondary succession stage. Brazilian Journal of Ecology 1(14):35-41.

Favila, M. \& HalfFter, G. 1997. The use of indicator groups for measuring biodiversity as related to community structure and function. Acta Zoológica Mexicana 72:1-25.

Flechtmann, C. A. H. \& Rodrigues, S. R. 1995. Insetos fimícolas associados a fezes bovinas em Jaraguá do Sul/SC. 1. Besouros coprófagos (Coleoptera: Scarabaeidae). Revista Brasileira de Entomologia 39(2):303-309.

HalfFter, G. 1991. Historical and ecological factors determining the geographical distribution of beetles (Coleoptera: Scarabaeidae: Scarabaeinae). Folia Entomológica Mexicana 82:195-238

HalfFter, G. \& Arellano, L. 2002. Response of dung beetles diversity to human-induced changes in a tropical landscape. Biotropica 34(1):144-154.

HALFFTER, G. \& EDMONDS, W. D. 1982. The nesting behavior of dung beetles (Scarabaeinae): An ecologic and evolutive approach. México D.F., Man and Biosphere Program UNESCO. 177p.

Halffter, G. \& Favila, M. E. 1993. The Scarabaeinae (Insecta: Coleoptera) an animal group for analyzing, inventorying and monitoring biodiversity in tropical rainforest and modified landscapes. Biology International 27:15-21.

HalfFter, G.; Favila, M. E. \& HalfFter, V. 1992. A comparative study of the structure of the scarab guild in Mexican tropical rain forests and derived ecosystems. Folia Entomológica Mexicana 84:131-156.

HalfFter, G. \& Matthews, E. G. 1966. The natural history of dung beetles of the Subfamily Scarabaeinae (Coleoptera: Scarabaeidae). Folia Entomológica Mexicana 12/14:1-312.

HAMmER, O.; HARPER, D. A. T. \& RYAN, P. D. 2001. PAST: Palaeontological Statistics software package for education and data analysis. Palaeontologia Electronica 4(1):9-9.

HANSKI, I. \& CAMBefort, Y. 1991. Competition in dung beetles. In: Hanski, I. \& Cambefort, Y. eds. Dung beetle ecology. Princeton, Princeton University Press, p.305-329.
Hickman, C. P.; Roberts, L. S. \& Larson, A. 2004. Princípios integrados de Zoologia. $11^{a}$ ed. Rio de Janeiro, Guanabara-Koogan. 872p.

Hofer, H.; Hamagarth, W.; Garcia, M.; Martius, C.; Franklin, E.; RombKe, J. \& BeCK, L. 2001. Structure and function of soil fauna communities in Amazonian anthropogenic and natural ecosystems. European Journal of Soil Biology 37(4):229-235.

HulBerT, S. H. 1971. Nonconcept of species diversity: A critique and alternative parameters. Ecology 52(4):577-586.

Koller, W. W.; Gomes, A.; Rodrigues, S. R. \& Goiozo, P. F. I. 2007. Scarabaeidae e Aphodiidae coprófagos em pastagens cultivadas em área do cerrado sul-mato-grossense. Revista Brasileira de Zoociências 9(1):81-93.

LARSEN, T. H. \& Forsyth, A. 2005. Trap spacing and transect design for dung beetle biodiversity studies. Biotropica 37(2):322-325.

Lobo, J. M.; Martín-Piera, F. \& Veiga, C. M. 1988. Las trampas pitfall con sebo, sus posibilidades en el estudio de las comunidades coprófagas de Scarabaeoidea (Col.). I. Características determinantes de su capacidad de captura. Revue d'Ecologie et de Biologie du Sol 25(1):77-100.

Lopes, J.; Korasaki, V.; Catelli, L. L.; Marçal, V. V. M. \& Nunes, M. P. B. P. 2011. A comparison of dung beetle assemblage structure (Coleoptera: Scarabaeidae: Scarabaeinae) between an Atlantic forest fragment and adjacent abandoned pasture in Paraná, Brazil. Zoologia 28(1):72-79.

Louzada, J. N. C. \& Lopes, F. S. 1997. A comunidade de Scarabaeidae copro-necrófagos (Coleoptera) de um fragmento de Mata Atlântica. Revista Brasileira de Entomologia 41(1):117-121.

Marchiori, J. N. C. 2002. Fitogeografia do Rio Grande do Sul Enfoque Histórico e Sistemas de Classificação. Porto Alegre, EST edições. 118p.

Marinoni, R. C. 2001. Os grupos tróficos em Coleoptera. Revista Brasileira de Zoologia 18(1):205-224.

Marinoni, R. C.; Ganho, N. G.; Monné, M. L. \& Mermudes, J. R. M; 2001. Hábitos alimentares em Coleoptera (Insecta). Ribeirão Preto, Holos. 63p.

MCNeELY, J. A. \& ScherR, S. J. 2009. Ecoagricultura: alimentação do mundo e biodiversidade. São Paulo, Senac Editora. 464p.

Milhomem, M. S.; VaZ-De-Mello, F. Z. \& DiniZ, I. R. 2003. Técnicas de coleta de besouros copronecrófagos no Cerrado. Pesquisa Agropecuária Brasileira 38(11):1249-1256.

Nichols, E.; Spector, S.; Louzada, J.; Larsen, T.; Amezquita, S. \& FAvila, M. E. 2008. Ecological functions and ecosystem services provided by Scarabaeinae dung beetles. Biological Conservation 141:1461-1474.

Oliveira-Costa, J. 2008. Entomologia Forense: quando os insetos são vestígios. 2ed. Campinas, Millenium. 420 p.

R Core Team. 2013. R: A language and environment for statistical computing. Austria, Vienna: R Foundation for Statistical Computing. Disponível em: <http://www.R-project.org/>. Acesso em: 10.04.2013.

Ribeiro - Costa, C. S. \& Rocha, R. M. 2006. Invertebrados: Manual de Aulas Práticas. 2ed. São Paulo, Holos. 271p.

Simmons, L. W. \& RidSDilL-Smith, T. J. 2011. Reproductive competition and its impact on the evolution and ecology of dung beetles. In: Simmons, L. W. \& RidSDILL-Smith, T. J. eds. Ecology and evolution of dung beetles. Oxford, Blackwell Publishing, p.1-20.

VAZ-DE-Mello, F. Z. 2000. Estado de conhecimento dos Scarabaeidae s. str. (Coleoptera: Scarabaeoidea) do Brasil. In: Martín-Piera, F.; Morrone, J. J. \& Melic, A. eds. Hacia un proyecto CYTED para el inventario y estimación de la diversidad entomológica en Iberoamérica. Zaragoza, Sociedad Entomologica Aragonesa. p.181-195.

Viegas, G.; Stenert, C.; Schulz, U. H. \& Maltchik, L. 2014. Dung beetle communities as biological indicators of riparian forest widths in southern Brazil. Ecological Indicators 36:703-710.

Waterhouse, D. F. 1974. The biological control of dung. Scientific American 230(3):100-109. 